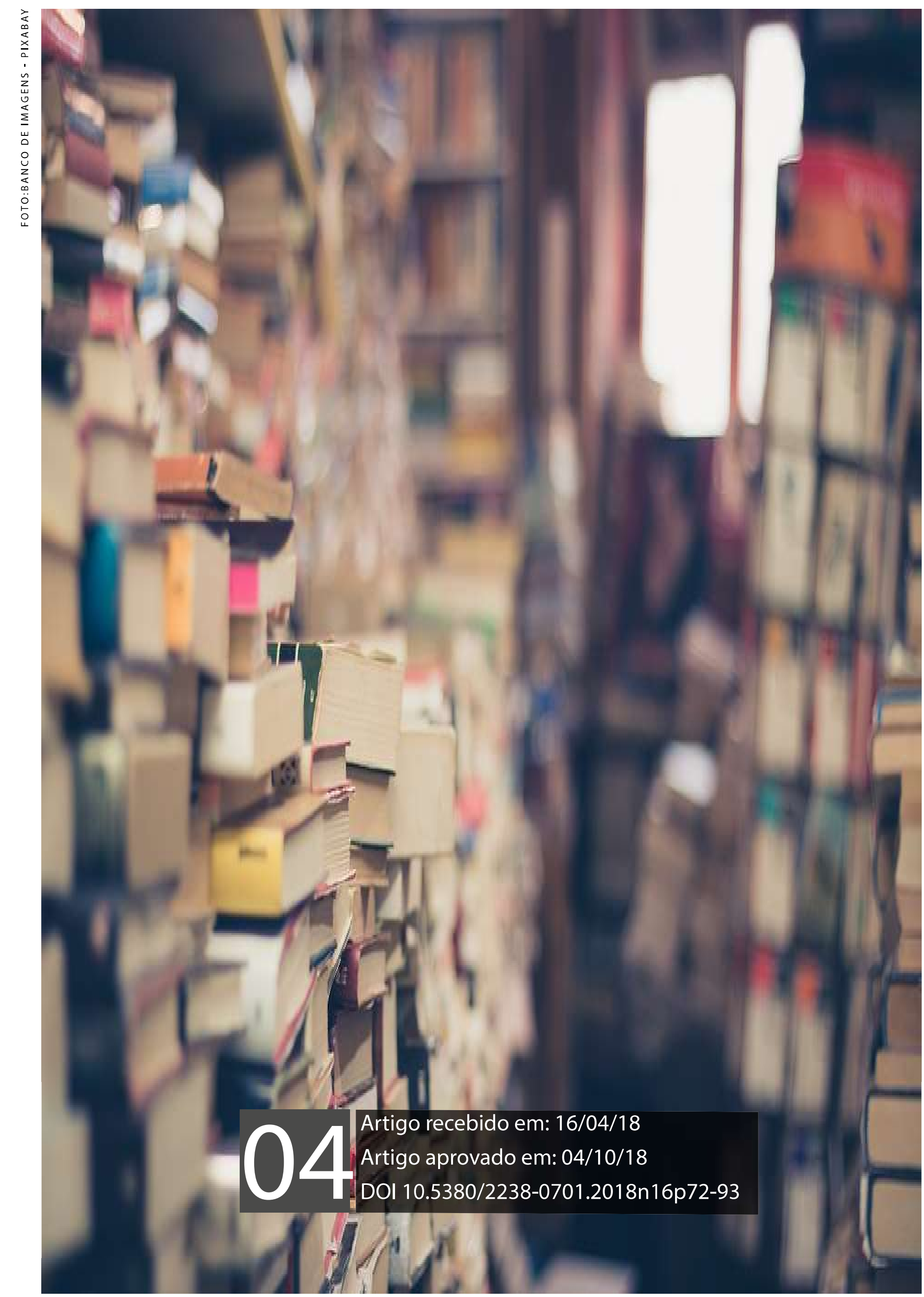


Autoajuda; Discursos da felicidade; Relações de saber e poder. 


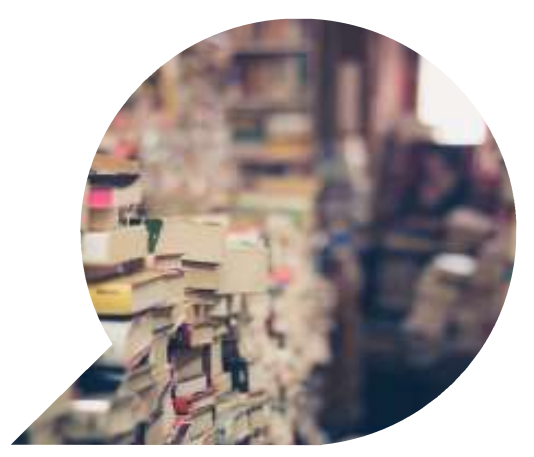

\title{
A felicidade é logo aqui: discurso e po- der na literatura de autoajuda
}

\author{
La felicidad es pronto aquí: discurso y poder en la literatura de \\ autoayuda
}

Happiness is here: discourse and power in self-help literature

GEILSON FERNANDES DE OLIVEIRA ${ }^{2}$

MARCÍLIA LUZIA GOMES DA COSTA MENDES ${ }^{3}$

Resumo: A literatura de autoajuda é um fenômeno que tem como uma das suas principais características o agenciamento de modos de ser e estar. Em seus enunciados, identificam-se regras, propostas de ações que uma vez acatadas, poderão, segundo estes manuais, indicar aos sujeitos o caminho da felicidade. Partindo dos pressupostos teóricos e metodológicos da Análise do Discurso de orientação francesa, são analisados os sentidos produzidos pelo

\footnotetext{
1 Uma versão preliminar deste artigo foi apresentada na Divisão Temática VII - Discursos e Estéticas da Comunicação, durante o XIV Congresso Internacional IBERCOM, na Universidade de São Paulo - USP, São Paulo, realizado de 29 de março a 02 de abril de 2015. Na versão atual, o texto teve suas discussões ampliadas e atualizadas.

2 Doutorando em Estudos da Mídia pela Universidade Federal do Rio Grande do Norte (UFRN). Jornalista e Mestre em Ciências Sociais e Humanas pela Universidade do Estado do Rio Grande do Norte (UERN). E-mail: geilson_fernandes@hotmail.com.

3 Doutora em Ciências Sociais pela Universidade Federal do Rio Grande do Norte (UFRN). Docente do Departamento de Comunicação Social e dos Programas de Pós-Graduação em Ciências Sociais e Humanas (PPGCISH) e Ciências da Linguagem (PPGCL) da Universidade do Estado do Rio Grande do Norte (UERN). E-mail: marciliamendes@uol.com.
} 
discurso da felicidade na literatura de autoajuda, tomando como recorte empírico de investigação a obra Doze semanas para mudar uma vida (2007), de Augusto Cury. Através de um processo de descrição e interpretação dos enunciados, identificam-se relações de saber e poder (FOUCAULT, 2013; 2013a), constituídas por discursos pedagógicos, nos quais os autores buscam mostrar-se como detentores de um saber não possuído pelos outros. Tais enunciados instituem regras, como o controle do tempo e o estabelecimento imperativo de modos de ser e estar por meio de ordens do discurso que patologizam os menos felizes.

Palavras-Chave: Autoajuda; Discursos da felicidade; Relações de saber e poder.

Resumen: La literatura de autoayuda es un fenómeno que tiene como una de sus principales características el agenciamiento de modos de ser y estar. En sus enunciados, se identifican reglas, propuestas de acciones que una vez acatadas, podrán, según estos manuales, indicar a los sujetos el camino de la felicidad. A partir de los presupuestos teóricos y metodológicos del Análisis del Discurso de orientación francesa, se analizan los sentidos producidos por el discurso de la felicidad en la literatura de autoayuda, tomando como recorte empírico de investigación la obra Doce semanas para cambiar una vida (2007), de Augusto Cury. A través de un proceso de descripción e interpretación de los enunciados, se identifican relaciones de saber y poder (FOUCAULT, 2013; 2013a), constituidas por discursos pedagógicos, en los cuales los autores buscan mostrarse como poseedores de un saber no poseído por los demás. Tales enunciados instituyen reglas, como el control del tiempo y el establecimiento imperativo de modos de ser y estar por medio de órdenes del discurso que patologizan a los menos felices

Palabras clave: Autoayuda; Discursos de la felicidade; Relaciones de conocimiento y poder. ${ }^{2}$

\footnotetext{
2 Uma versão preliminar deste artigo foi apresentada na Divisão Temática VII - Discursos e Estéticas da Comunicação, durante o XIV Congresso Internacional IBERCOM, na Universidade de São Paulo - USP, São Paulo, realizado de 29 de março a 02 de abril de 2015. Na versão atual, o texto teve suas discussões ampliadas e atualizadas.
} 
Abstract: The self-help literature is a phenomenon that has as one of its main characteristics the agency of ways of being and being. In their statements, they identify rules, proposals of actions that once acted, can, according to these manuals, indicate to the subjects the path of happiness. Starting from the theoretical and methodological assumptions of the French Orientation Discourse Analysis, we analyze the meanings produced by the discourse of happiness in the self-help literature, taking Augusto Cury's Twelve Weeks to Change a Life (2007) as an empirical research. Through a process of description and interpretation of statements, we identify relations of knowledge and power (FOUCAULT, 2013; 2013a), constituted by pedagogical discourses, in which the authors seek to show themselves as holders of a knowledge not possessed by others. Such statements institute rules, such as the control of time and the imperative establishment of ways of being and being by means of discourse orders that pathologize the less happy.

Keywords: Self Help. Happiness speeches. Relations of knowledge and power. 


\section{Introdução}

Na contemporaneidade, os ideais de felicidade são a cada dia mais buscados. Ao se falar em felicidade, não podemos deixar de lado a sua propagação por meio do fenômeno denominado como literatura de autoajuda, compreendendo livros dos mais diversos que propagam através de seus discursos o aprimoramento pessoal e a felicidade nos distintos âmbitos da vida dos sujeitos, através de fórmulas para o emagrecimento ${ }^{3}$, superar a timidez $z^{4}$, aprender a ser líder ${ }^{5}$, ser feliz ${ }^{6}$, etc. A literatura de autoajuda vem se mostrando como um dos principais produtos da indústria cultural no que concerne aos aconselhamentos de como lidar com os vários e distintos problemas do cotidiano, ofertando medidas e fórmulas de superação que podem levar o sujeito ao caminho da felicidade e, mais do que isso, a sua consecução, conforme anunciam.

Diante disso, no presente artigo objetivamos, a partir dos pressupostos teóricos e metodológicos da Análise do Discurso de orientação francesa, analisar os sentidos produzidos sobre a felicidade na literatura de autoajuda, atentando, especificamente, para as relações de saber e poder que apresentam. Para tanto, a partir de um viés eminentemente qualitativo, tomamos como recorte empírico de investigação é a obra Doze semanas para mudar uma vida (2007), do escritor Augusto Cury, um dos principais expoentes deste tipo de literatura em nosso país. Através de um processo de descrição e interpretação dos enunciados que compõem o corpus, buscamos refletir e analisar o engendramento de tais relações e seus agenciamentos.

O tipo de literatura que deu origem ao gênero autoajuda formou-se a partir de transformação sociais, históricas e culturais, as quais possibilitaram mudanças na percepção sobre o poder da mente, decorrente especialmente pela difusão da cultura de massa, sugere Rüdiger (1996). Esse fenômeno literário teve como percussor expressivo um livro homônimo ao título do gênero: Self-Help (autoajuda), do médico e publicista Samuel Smiles, em

\footnotetext{
3 A dieta da barriga zero! Perca até $7 \mathrm{~kg}$ em 32 dias (SASS, Cynthia; VACCARIELO, Liz. Editora Best-Seller, 2011); Dieta dos 10 passos (JUNIOR, Jair Garcia. Phorte Editora, 2007); Dieta nota 10: comer e emagrecer é mais simples do que se imagina (RIBEIRO, Guilherme de Azevedo. Bertrand Brasil, 2011), entre outros.

4 Manual de sobrevivência dos tímidos (MARON, Bruno. Editora Lote42, 2013); Como vencer a timidez (ALBISETTI, Valério. Paulinas, 2004); Timidez: como ajudar seu filho a superar problemas de convívio social. EISEN, Andrew R; ENGLER, Linda B. Editora Gente, 2008), entre outros.

5 Seja líder de si mesmo (CURY, Augusto. Editora Sextante, 2004); 0 monge e o executivo (HUNTER, James C. Editora Sextante, 2004), entre outros.

6 Os 100 segredos das pessoas felizes (NIVEN, Savid. Editora Sextante, 2002); Felicidade: a prática do bem-estar (MATTHIEU, Ricard. Editora Palas Athena, 2007); entre muitos outros.
} 
1859. A obra consiste em uma série de palestras proferidas pelo autor para um grupo de trabalhadores que tinham aprendido a ler e a escrever, além de estudar outras disciplinas, de forma autônoma. A partir de Self-Help, Smiles buscava mostrar aos leitores, o quanto nós podemos ajudar a nós mesmos e, principalmente, o quanto "a felicidade e o bem-estar individuais do decurso da vida dependem principalmente e necessariamente de nós" (SMILES, 1859 apud RÜDIGER, 1996, p. 33). Com proposta inovadora para a época, esta é a obra de maior sucesso de Smiles, que também produziu outros livros com temáticas semelhantes ${ }^{7}$.

Como parte da lógica da indústria cultural, a autoajuda é vista como uma das instâncias propagadoras da felicidade, logo, uma indústria em crescimento. Schoch (2011, p. 11) demonstra a extensão dessa indústria em valores monetários, apontando que "os livros de autoajuda geram vendas de US\$1 bilhão anualmente [...]”. Nesse cenário, o Brasil é, conforme Tucherman (2012), o segundo maior público consumidor do gênero. Afunilando essa discussão, Freire Filho (2010) mostra que de acordo com dados da Câmara Brasileira do Livro (CBL), consultados por ele em 2010, o segmento da literatura de autoajuda cresceu, em nosso país, de 5\% a $10 \%$ ao ano, entre 1996 e 2006. Conforme esses dados, no ano de 2006, cerca de 600 novos livros do gênero foram lançados, compreendendo inclusive obras direcionadas ao público infantil ${ }^{8}$. Ainda, segundo pesquisa realizada pela Associação Nacional de Livrarias (ANL, 2012), os livros desse nicho editorial apresentam-se na $4^{a}$ posição da lista de classificação dos gêneros mais comercializados no Brasil, demonstrando, além disso, que de 2009 para 2012, a comercialização dessas publicações teve $23 \%$ de crescimento, percentual ainda mais expressivo em relação aos apresentados por Freire Filho em 2010.

Para se ter uma noção da popularidade e sucesso do gênero autoajuda, desde 1983, o New York Times criou estrategicamente uma forma de divulgar a lista dos livros mais vendidos, criando uma nova categoria - "Advice" (conselho) -, e esta tornou-se especial para os livros de aconselhamentos. A necessidade de sua criação mostrou-se importante e justificável, pois, como afirma Tucherman (2012, p. 137), "se isso não fosse feito, nunca mais nenhum livro de não ficção poderia aparecer como sendo um dos mais vendidos". A mesma estratégia foi tomada como modelo pela Revista Veja a partir

7 O poder da vontade (1865), O Caráter (1875) e O dever (1880).

80 livro Agapinho: ágape para crianças, do Padre Marcelo Rossi (Editora Globo, 2012) é um exemplo de títulos de autoajuda voltados para o público infantil. 
de 1989 e, conseguintemente, por muitas outras empresas. Do sucesso na carreira profissional ao êxito amoroso, as obras colocam em cena o discurso de que não existe mais nenhum domínio da existência humana que não possa ser aprimorado. Assim, fornecem a uma massa de leitores ávidos novas estratégias e técnicas de fácil compreensão, objetivando maximizar a sua existência subjetiva. A felicidade torna-se, então, um imperativo (BIRMAN, 2010) e surge uma indústria do bem-estar e do aprimoramento pessoal.

A literatura do gênero é formada por manuais e textos práticos, os quais indicam métodos e formas de bem viver, obter sucesso material - a riqueza, trabalho, etc. -, e sucesso pessoal - a felicidade, o emagrecimento, o encontro de parceiros amorosos, superação da timidez, etc. Também podem ser encontrados neste gênero relatos pessoais, com histórias de vida de sucesso - material e pessoal - apresentando as maneiras utilizadas para superar as adversidades e torna-se uma "nova pessoa" (RÜDIGER, 1996). Nas obras, o pressuposto básico é a noção de que o bem-estar subjetivo será alcançado através de um condicionamento positivo e disciplinamento pessoal.

São livros que atendem as demandas latentes e obtêm, por consequência, grande sucesso de público, tendo em vista o seu "pedagogismo", isto é, enunciados que visam adequar o sujeito leitor aos discursos dominantes, tranquilizá-los por meio dos sentidos produzidos. Os títulos da literatura de massa, e aqui enquadramos a autoajuda, são manifestações de um discurso que é resultante das tendências e exigências geradas pela sociedade moderna. Uma prova disto, defende Sodré (1988) é que a indústria editorial responsável pelas publicações desse tipo investe continuamente neste nicho já há algum tempo, sem ainda demonstrar ter sofrido prejuízos.

Basta olharmos a quantidade de títulos lançados para repararmos esta questão. No Brasil, o autor mais lido do país nos últimos dez anos, segundo o Jornal Folha de São Paulo e Revista Isto $E^{9}$, por exemplo, foi Augusto Cury, escritor conhecido por suas inúmeras obras de aprimoramento pessoal. Seus livros já foram publicados em mais de 60 países, sendo traduzido para diversos idiomas e vendendo mais de 20 milhões de exemplares somente no Brasil.

Das muitas obras do autor, Doze semanas para mudar uma vida (2007) é uma das que obtiveram grande sucesso e repercussão no seu período de lançamento, ficando por algum tempo entre as obras mais vendidas do país,

9 Conforme informações publicadas em <http://www1.folha.uol.com.br/folha/ilustrada/ ult90u600189.shtml> e <http://www.istoe.com.br/reportagens/142655_0+MAIOR+VENDEDOR+DE+LIVROS+DO+BRASIL>. Acesso em: 12.07.2015. 
sendo, além disso, ainda nos dias de hoje largamente comercializada e consumida em seus mais diversos formatos.

\section{A análise do discurso de orientação francesa}

Enquanto método legitimado pela ciência para objetos de pesquisa sob o enfoque da linguagem, a Análise de Discurso (AD) de orientação francesa é considerada profícua para estudos nas áreas das ciências sociais e humanas, buscando ora o mapeamento das vozes, ora a identificação dos sentidos (BENETTI, 2016).

Segundo Gill (2002), a análise do discurso trabalha uma perspectiva que rejeita a noção da linguagem ou dos discursos como um meio neutro de refletir ou descrever o mundo, sendo mais do que isso, de suma importância para a construção do mundo social da forma que conhecemos, haja vista as suas complexas implicações. Por sua vez, em relação especificamente à AD de origem francesa, Gill (2002, p. 247) elenca que esta rompe com as visões da linguagem como algo transparente e rejeita a noção de um sujeito unificado e coerente, opondo-se ao mesmo tempo a visão de uma história universal, interessando-se não pelos aspectos textuais, gramaticais ou dos atos de fala, mas pelos discursos, vistos através de uma perspectiva social e histórica. Com efeito, "A linguagem, então, não é vista como um mero epifenômeno, mas como uma prática em si mesma" (GILL, 2002, p. 248).

Tendo suas raízes no campo da linguística, a Análise do Discurso vem sendo bastante utilizada no campo de estudos do campo da comunicação e da mídia em pesquisas que lidam com investigações relacionadas às construções políticas e/ou sociais, assim como para reflexões que lidam com produções de sentidos, as relações de poder, processos de subjetivação e constituição do sujeito. No Brasil, os estudos em torno da $\mathrm{AD}$ vêm se desenvolvendo desde o final da década de 1970, consolidando conforme Gregolin (2003, p. 10) um campo fértil para investigações que associam as pesquisas linguísticas com contextos e problemáticas sociais da história.

Visualizando o discurso como algo impregnado de aspectos sociais, políticos e históricos, para Foucault (2011), autor que promove a partir de suas ideias e perspectivas reapropriações e novos caminhos teóricos e epistemológicos para a $\mathrm{AD}$, o trabalho de se analisar os discursos poderia ser visto como um trabalho efetivo dos historiadores. Apoiando esta perspectiva, Gill (2002, p. 248) afirma que durante o processo de análise, o analisa do discurso deve estar atento e envolvido simultaneamente em analisar o dis- 
curso e o seu contexto interpretativo, ou seja, as condições que favoreceram a emergência de determinadas práticas discursivas. Daí a necessidade de se ter conhecimentos acerca das instâncias de produção em que emergiram os discursos e quais os fatores que influenciaram a sua irrupção e seus efeitos de sentidos. Evidencia-se, desta forma, a importância de se conhecer a conjuntura histórica, política e social de produção dos discursos analisados.

Foucault (2013a) rejeita a percepção de discurso como um conjunto de signos, visto como um elemento que possui um significante dado. Obviamente, destaca o filósofo, os discursos são também compostos de signos, mas possuem algo a mais, e é justamente este "mais" que tem que ser buscado e analisado. Os sentidos dos discursos que compõem o nosso corpus, dessa forma, não estão no livro propriamente dito ou nos signos que possui. Há algo a mais, como por exemplo, qual o porquê da recorrência destes discursos na contemporaneidade e não outro? Quais são as condições de possibilidade que favoreceram o seu surgimento e impulsionam o seu êxito? De que forma estes discursos trabalham com a questão da felicidade? Quais as relações de saber e poder que os atravessa?

Em se tratando da questão dos procedimentos de análise, não há uma receita exata em torno da aplicação da AD. Como bem destaca Gill (2002, p. 250), "seria muito agradável se fosse possível oferecer uma receita, ao estilo de manuais de cozinha, que os leitores pudessem acompanhar, metodicamente; mas isso é impossível". Contudo, a autora salienta que "fazer análise de discurso implica questionar nossos próprios pressupostos e as maneiras como nós habitualmente damos sentido as coisas" (GILL, 2002, p. 252), de modo que não só o que é enunciado produz sentidos, mas também aquilo que é silenciado.

Destarte, uma das principais características é que o trabalho do analista do discurso não é um exercício linear de análises, mas um percurso feito de idas e vindas ao material analisado e ao aporte teórico, visando promover a efetivação das análises por meio da descrição e interpretação dos enunciados em um mesmo tempo (GREGOLIN, 2003), itinerário que será seguido nas análises apresentadas a seguir.

\section{Semanas para mudar uma vida: autoajuda e discurso pedagógico}

A questão da analítica do poder é um dos pilares centrais das teses foucaultianas, principalmente durante a fase genealógica. A discussão que engloba esta temática é de grande importância para analisarmos a proble- 
mática da literatura de autoajuda. Conforme os postulados de Michel Foucault (2013), o poder não possui um ponto específico, mas atravessa todo o tecido social. Mais incisivamente, o autor chega a afirmar que o poder não existe, mas o que existe são relações de poder, as quais não são derivadas de uma ordem natural, mas, prática social constituída nas tramas históricas.

Enquanto manifestação do social e parte dessa rede, a literatura de autoajuda evidencia em muitos momentos as relações de poder, principalmente pelas noções de treinamentos, técnicas de aprimoramento de si, as quais revelam um sentido de dependência e baixa da autonomia por parte dos sujeitos para lidar com os seus próprios problemas. Treinar as emoções para superar aos outros e principalmente a si mesmo para que assim possa atingir altas performances e ser feliz, esta é a lógica proposta de forma imperativa pelos discursos de autoajuda, de forma específica, no livro 12 semanas para mudar uma vida (CURY, 2007).

$\mathrm{Na}$ literatura de autoajuda, as relações de poder podem ser percebidas desde o título das obras. Em 12 semanas para mudar uma vida (CURY, 2007), por exemplo, identificamos um sentido de treinamento e a promessa de mudanças positivas em um período de 12 semanas - "[...] A meta principal é que o programa nele contido seja executado em doze semanas. Em cada semana será vivenciada uma lei da qualidade de vida, um capítulo" (CURY, 2007, p. 30), desde que o leitor cumpra com as orientações que são dispostas. Também se evidência o controle do tempo - 12 semanas - e o seu disciplinamento para que haja mudanças positivas. Um controle minucioso, não mais pautado por punições, como discutido por Foucault (2003) em Vigiar e Punir, mas que faz uso das potencialidades dos próprios sujeitos.

$\mathrm{O}$ adestramento do corpo, das ações e dos pensamentos são trabalhados a todo tempo pela obra analisada. Além do título, em 12 semanas para mudar uma vida (2007) percebe-se a divisão dos capítulos conforme orientações práticas, colocadas em formato de leis - uma legislação para a qualidade de vida e a felicidade, dois pontos apresentados como se um fosse o sinônimo do outro. Leis assim expressas: $1^{a}$ lei da qualidade de vida (capítulo 1), $2^{a}$ lei da qualidade de vida (capítulo 2) e assim sucessivamente, as quais hipoteticamente podem favorecer a mudança de vida e a superação.

Nos enunciados que constituem os subtítulos dos doze capítulos, nove se iniciam com verbos imperativos no infinitivo, tais como ser, contemplar, libertar, superar, ter, gerenciar, administrar, trabalhar e fazer, o que indica

10 Com o objetivo de distinguirmos as citações diretas da obra analisada - 12 Semanas para mudar uma vida, estas serão apresentadas em itálico, diferindo-se das demais consultadas. 
a necessidade de sua execução no tempo presente, no agora. Ao colocar as suas orientações como leis, percebe-se o lugar de autoridade do qual o autor busca falar, dando o sentido legitimador máximo (em forma de leis) às suas orientações, fator que expressa ordem e disciplina, evocando um regime de regras para a felicidade.

Também é interessante notar a supervalorização destinada para os leitores, sempre colocados em posições que possam lembrar ou relembrar os seus êxitos e vitórias. No entanto, ao mesmo tempo em que há essa supervalorização, através do uso de superlativos e de adjetivos positivos, o que pode ser considerada como uma estratégia, logo se coloca a necessidade da superação. Emerge, então, o sentido de que o sujeito por si só já é vitorioso, mas somente isto já não basta, é preciso superar-se, é preciso treinar as suas emoções e ser cada vez mais feliz, e é para isto que o sujeito é convocado, de modo que a partir da leitura e execução dos treinamentos "você não será mais o mesmo e nem a sociedade. Faça diferença no mundo. Participe desse sonho" (CURY, 2007, p. 14).

Antes que seja iniciada a leitura do livro 12 semanas para mudar uma vida, no entanto, é sugerido que o leitor faça uma avaliação da sua qualidade de vida. Esta mesma avaliação deverá ser feita após o término da leitura, o que poderá demonstrar se ela foi positiva ou não para o leitor, bem como conferir quais as características "doentias" (CURY, 2007, p. 34) ele conseguiu melhorar ou superar. A avaliação consiste em um questionário para marcação dos "sintomas" psíquicos e psicossomáticos que os sujeitos enfrentam. O quadro de avaliação é o seguinte (Figura 01).

No quadro, são apresentados 18 sintomas de cada categoria (sintomas de problemas psíquicos e de problemas psicossomáticos), totalizando 36. No mundo contemporâneo, não é difícil que os sujeitos marquem vários sintomas, o que também não pode ser visto como algo determinante.

A priori, o uso dos verbetes "sintoma" e características "doentias" já direciona para o sentido de saúde e doença, estabelecendo quem está dentro da ordem do discurso da felicidade - os que se reconhecerem com poucos "sintomas", e os que estão fora e são vistos como doentes, logo, patologizados - aqueles que identificam a partir do teste possuírem mais do que o indicado (considerado comum) dos "sintomas", desvelando um jogo de classificação e diferenciação.

Na página seguinte ao questionário, há uma classificação da qualidade de vida de acordo com o número de sintomas expressos em resposta ao questionário disposto anteriormente (figura 1). 


\section{Sintomas psíquicos}

\begin{tabular}{|l|l|}
\hline ( ). Cansaço exagerado & ( ). Perda do prazer de viver \\
( ). Pensamento acelerado & ( ).Tristeza ou humor deprimido \\
( ). Insônia & ( ). Falta de concentração \\
( ). Excesso de sono & ( ).Sofrimento por antecipação \\
( ). Esquecimento & ( ).Angústia (ansiedade + aperto no peito) \\
( ). Desmotivação, desânimo & ( ). Agressividade \\
( ).Diminuição do prazer sexual & ( ). Sentimento de culpa intenso \\
( ). Baixa auto-estima & ( ). Solidão \\
(). Medo & (). Idéia de desistir da vida \\
\hline
\end{tabular}

\section{Sintomas psicossomáticos}

\begin{tabular}{|l|l|}
\hline ( ). Dor de cabeça & ( ). Hipertensão quando está tenso. \\
( ). Falta de ar & ( ). Diarréia quando está tenso \\
( ). Tontura & ( ). Aumento do apetite \\
( ). Taquicardia & ( ). Diminuição do apetite \\
( ). Nó na garganta & ( ). Excesso de suor \\
( ). Aperto no peito & ( ). Choro ou vontade de chorar \\
(). Dores musculares & ( ). Mãos frias é úmidas \\
( ). Prurido (coceira) & ( ). Queda de cabelo \\
( ). Gastrite & (). Nenhum \\
\hline
\end{tabular}

Figura 1 - Questionário de avaliação da qualidade de vida (CURY, 2007, p. 35).

Analisando o questionário e considerando a quantidade de itens-sintomas, nota-se que a classificação da qualidade de vida (figura 2) se mostra como muito radical, senão pessimista e extremista, pois, se de um total de 36 sintomas, o leitor tiver ao menos $10^{11}$, já é considerado como possuidor de uma qualidade de vida péssima, salientando mais uma vez que o sentido de qualidade de vida é posto de modo muito semelhante ao sentido de felicidade. De acordo com esta contabilização, retornamos outra vez para a patologização dos "menos felizes" ou dos que possuem, na visão do autor, "uma inteligência emocional" mais deficitária, construindo uma fronteira simbólica entre os insiders (felizes) e outsiders (infelizes).

11 Quantidade equivalente a 27,7\% das respostas. 


\title{
Classificação da qualidade de vida
}

\author{
Sem sintomas: \\ Qualidade de vida excelente \\ 1 - 2 sintomas: \\ Qualidade de vida boa \\ 3 - 4 sintomas: \\ Qualidade de vida regular \\ 5 - 9 sintomas: \\ Qualidade de vida ruim \\ Dez ou mais sintomas: Qualidade de vida péssima
}

Figura 2 - Classificação da qualidade de vida (CURY, 2007, p. 36).

Diante de uma "consulta" que implique em descobertas tão impactantes com relação à qualidade de vida e à felicidade, é provável que a leitura da obra será levada adiante por aqueles que já buscam o livro frente a outras necessidades, as quais são ampliadas. Após passar por este teste e ver o seu resultado no quadro de classificação, o autor indica ao leitor que independente do saldo - se positivo ou negativo -, haverá a necessidade de aplicação do PAIQ (Programa da Academia da Inteligência de Qualidade de Vida), através da leitura do livro e do exercício das técnicas inerentes ao programa. Para aqueles que estão menos felizes e tem uma qualidade de vida mais deficitária conforme os pressupostos, o $P A I Q$ deve ser utilizado para conseguir reverter este quadro; já para aqueles que não estão em situação negativa, para poder proporcionar uma vida melhor ainda, potencializando as possibilidades de felicidade. Percebe-se, com isto, que a felicidade nunca é demais, sempre podendo ser trabalhada e potencializada por meio de técnicas e treinamentos "originais".

Segundo Augusto Cury, o PAIQ é fundamentado na teoria da Inteligência Multifocal ${ }^{12}$, base dos seus livros, "uma teoria original, mas abrangente, pois envolve os pontos fundamentais das principais teorias psicológicas da atualidade" (CURY, 2007, p. 20). Ao afirmar a originalidade de uma teoria contem-

12 Título de outra obra de Augusto Cury - Inteligência Multifocal, São Paulo, Cultrix, 1998; que inclusive chega a ser indicada para os leitores. Segundo Cury, a inteligência multifocal diz respeito a uma teoria que tem sido estudada por diversos cientistas em vários países, chegando inclusive a ser inserida nas grades curriculares de alguns cursos universitários. É uma teoria que visa investigar os fenômenos da inteligência humana a partir de quatro processos da psique ou mente humana: "1 - a formação de pensamentos; 2 - a transformação da energia psíquica; 3 - a formação da consciência e dos alicerces do "eu"; 4 - os papéis da memória e a formação da história existencial" (CURY, 2007, p. 20). 
porânea, esta enunciação produz sentidos controversos com outros discursos da atualidade, pois muito se têm debatido em nossos dias sobre o fim das grandes narrativas e a impossibilidade do novo. Com esta afirmação, Cury evoca o sentido da novidade de seu programa, um produto recém-lançado em um mercado autoapresentado com muitas inovações, mas dificilmente originais. Ele complementa, atestando que no mesmo instante em que é original, é uma teoria universal, podendo ser usadas nas áreas da psicologia, educação, sociologia e psiquiatria e aplicada junto a qualquer povo, cultura, nação, crença e camada social. $\mathrm{O}$ autor chega, inclusive, a sugerir a introdução do $P A I Q$ nos currículos escolares - "O PAIQ pode ser introduzido também como nova disciplina na grade curricular das escolas e revolucionar a educação" (CURY, 2007, p. 19), fator explicitado a partir de um roteiro com orientações para a utilização do programa nas escolas, disponível nos apêndices do livro.

Dessa forma, mais uma vez procura-se mostrar o quanto as teorias trabalhadas no $P A I Q$ - apresentadas no livro - são eficientes. Já não basta dar conta de todos aqueles problemas anteriormente explicitados, ainda pode ser usado em diversas áreas e, responsável, sozinha, por uma revolução na educação: “Cremos que esse programa cumpre o sonho de Moisés, Maomé, Confúcio, Agostinho, Platão, Piaget, Freud, Paulo Freire, Einstein, enfim, dos grandes pensadores: formar seres humanos livres" (CURY, 2007, p. 243). Ou seja, eis diante dos sujeitos a possibilidade de resolução de todos os problemas. Ademais, tendo em vista a dita complexidade do programa, o autor argumenta que ele foi traduzido para os leitores, objetivando "[...] que qualquer pessoa possa ter acesso às suas ferramentas” (CURY, 2007, p. 22).

Com estes enunciados, Cury busca aproximar-se de um outro tipo de discurso: o científico. Isso é percebido de modo explícito no livro analisado. Nele, Cury cita pesquisas, experimentos e os seus resultados. Frequentemente é feito o uso da citação de si próprio, de suas outras obras. Entretanto, raramente faz uso de outras vozes do discurso científico, apesar de apresentar ao final do livro considerável bibliografia, incluindo pensadores como Freud, Erich Fromm, Platão, Descartes, Carl G. Jung, etc. Estas referências manifestam pretensões ao discurso científico, a uma vontade de verdade para caracterizar o próprio discurso. A visibilidade dada a estes pensadores expostos em suas referências, mesmo sem citá-los, pode contribuir para uma maior confiança por parte daqueles que leem a obra. Demonstrando possuir conhecimentos de seus argumentos a partir da pretensão de um discurso científico, as orientações ganham maior validade, legitimidade e conferem a Cury a retórica de um sujeito que sabe do que está falando junto aos seus leitores. 
A obra de Augusto Cury propõe um treinamento das emoções durante 12 semanas para o aprimoramento pessoal e para o encontro da felicidade. E o autor faz uso de elementos que possam reforçar as questões que estão sendo apresentadas. Cury se mostra como não sendo qualquer pessoa que simplesmente escreve sobre o tema abordado sem possuir conhecimentos sobre o assunto. Ele se coloca na posição de médico, psiquiatra, pesquisador e escritor, o que dá um peso diferente à sua fala e às suas orientações. A posição-sujeito demarcada por Augusto Cury é atravessada por relações de saber-poder (FOUCAULT, 2013; 2013a), mostrando-se como possuidor de um tipo de saber raro, logo, possuindo também um tipo de poder. Afora a autoapresentação, no decorrer do texto há outros aspectos que convergem para um lugar de fala que se propõe diferenciado. Augusto Cury se posiciona como um estudioso e pesquisador, chegando inclusive a citar dados de pesquisas, outras obras de sua autoria - como já abordamos - e até uma teoria que afirma ter desenvolvido - teoria da inteligência multifocal.

Com estes aspectos, o autor constrói o que Maingueneau (2011) chama de ethos discursivo, ou seja, a construção de uma imagem de si por meio do discurso. O conceito de ethos abordado por Maingueneau (2011) distingue-se daquele da retórica aristotélica. Conforme o autor, o ethos discursivo pode ser entendido como a construção de uma imagem de si refletida no discurso, sustentando que, mesmo quando se trata de um texto escrito nosso caso -, este é sustentado por uma voz, uma imagem, questão que é apoiada com a concepção de Amossy (2011).

Todo ato de tomar a palavra implica a construção de uma imagem de si. Para tanto, não é necessário que o locutor faça seu autorretrato, detalhe suas qualidades nem mesmo que fale explicitamente de si. Seu estilo, suas competências linguísticas e enciclopédicas, suas crenças implícitas são suficientes para construir uma representação de sua pessoa. Assim, deliberadamente ou não, o locutor efetua em seu discurso uma apresentação de si (AMOSSY, 2011, p. 9).

Todavia, é importante ressaltar que o sujeito pode produzir imagens distintas de si a partir do discurso, isto é, utilizar elementos que divergem da realidade. No caso de Augusto Cury, não podemos inferir, por exemplo, se o ethos discursivo que é produzido corresponde à realidade, mas podemos, a partir do discurso que ele produz, construir e identificar imagens que são produzidas pelos efeitos de sentido.

No caso do autor, observamos que ao mesmo tempo em que ele se co- 
loca como o orientador, também demonstra que se submete aos treinamentos propostos. Isto propicia ao leitor o sentido de que o autor, assim como quem está buscando as respostas partilham de um mesmo sentimento, contribuindo para uma maior proximidade por parte daquele que lê em relação aquele que é lido. Em seu ethos discursivo, conceito atravessado por relações de saber-poder, notamos o lugar de autoridade em que o autor busca falar, apresentando exemplos de clientes que após passarem por consultas com ele obtiveram êxito.

Ao demonstrar somente exemplos de sucesso, constrói-se uma identidade de profissional exemplar e renomado, que conseguiu chegar a tal ponto a partir do treinamento de suas emoções. São utilizadas estratégias para validar os seus discursos, bem como para evidenciar o sucesso de suas orientações, junto a indivíduos distintos. Para o leitor, constrói-se um imaginário ao redor deste orientador e de sua obra. Produz-se o sentido de que após a leitura, o sucesso logo será encontrado.

O ethos discursivo do autor, inclusive, propõe-se como distinto do de autores de obras do gênero de autoajuda: "Este livro não é de auto-ajuda, mas de divulgação científica" (CURY, 2007, p. 30). Ao colocar-se como oposto da literatura de autoajuda o autor busca reforçar o sentido de cientificidade de sua obra, que ao contrário do gênero citado, possui maior respeito e credibilidade, podendo trazer um sentido cientificamente testado sobre uma vida saudável, ou seja, sobre a felicidade (MENDES, OLIVEIRA, 2013). Observa-se neste quesito a tentativa de uma diferenciação, tendo em vista que os manuais de autoajuda não são tidos como científicos, sendo geralmente mal vistos pela comunidade acadêmica. No entanto, é importante destacar que a obra de Augusto Cury é considerada por alguns críticos como sendo de autoajuda - ou autoajuda científica, tomando por base as ideias de Rohden (2012), tendo em vista que não fornece discussões teóricas e conceituais a ponto de ser apreciada como produzida nos moldes tradicionais da cientificidade, pautado pelo rigor e objetividade, mas populariza conhecimentos científicos de um campo do conhecimento - a psicologia positiva.

De todo modo, a partir dos enunciados analisados, são observadas as relações de poder e os lugares de produção dos discursos. Como aborda Orlandi (1999), "[...] o lugar a partir do qual o sujeito fala é constitutivo do que ele diz. Assim, se o sujeito fala a partir do lugar de professor, suas palavras significam de modo diferente do que se falasse do lugar de aluno" (ORLANDI, 1999, p. 39-40). Nesta trama de relações, observam-se ethos discursivos variados de Augusto Cury. Ora como médico, ora como amigo, alguém 
próximo que já possui algum tipo de intimidade com o leitor. Um cientista conhecedor do caminho da felicidade que possui tanto teorias, quanto inúmeras técnicas para se atingir o bem-estar subjetivo que tem se tornado a cada dia mais um imperativo: a felicidade (FREIRE FILHO, 2010). Ao se posicionar dessa forma, percebem-se as relações de poder-saber, já que Augusto Cury, sujeito que possui todos estes conhecimentos, possui um saber tão almejado por todos, um saber que também se constitui enquanto poder, mas não um poder vertical, mas horizontalizado, perpassando todas as redes de relações e possibilitando modos diversos de (re)apropriação.

Cury sugere com o seu saber a necessidade urgente para o treinamento da felicidade, que pode ser obtida pela leitura de sua obra. A superação e a felicidade são postas como imperativos, e instituem-se assim relações de poder-saber e saber-poder, uma vez que, como apregoam tais discursos, se o sujeito obtiver os conhecimentos para os treinamentos propostos, terá um tipo de poder sobre si mesmo e os seus rendimentos, sejam materiais ou subjetivos. O sujeito e as suas emoções passam a ser o objeto das relações de saber e poder, constituindo uma verdadeira economia.

\section{Considerações finais}

A literatura de autoajuda vem se apresentando como um dos fenômenos de maior expressão cultural e social. Sendo resultante de condições históricas e sociais que possibilitaram o seu surgimento, assim como o seu sucesso, percebemos no gênero, especialmente em 12 semanas para mudar uma vida (2007), relações de saber e poder que visam lidar diretamente com as subjetividades dos seus sujeitos leitores.

A partir das condições de possibilidades dadas, os discursos pedagógicos e prescritivos da autoajuda vêm ganhando cada vez mais sucesso e repercussão por meio da movimentação dos seus discursos, práticas, signos e significados na dispersão da história. Através desse gênero, as pessoas buscam adaptar-se, reconstruir-se segundo regras que, em um tom imperativo, assemelham-se a leis, as quais deverão ser cumpridas, ou então, caberá ao leitor simplesmente o fracasso, ficar à margem daquilo que doravante lhe é tão facilmente ofertado.

Neste regime, é preciso ser o Outro da felicidade, possuir total domínio e governo sobre si, ser aquele que possui a felicidade em altos níveis e não se envergonha, pois este sentimento é factível daqueles outros que não vivenciam esse bem-estar subjetivo. $\mathrm{O}$ culto da performance cada vez mais 
convocado pelos desígnios da literatura de autoajuda impõe que a felicidade não pode ser qualquer coisa, mas as experiências mais intensas e duráveis, inclusive, se possível, por toda a eternidade. Esse é o normal da felicidade propagado por estes discursos. O seu contrário é o anormal, patológico, próximo da doença e expressão de vergonhas e inconformidades.

Diante desse cenário, o discurso da autoajuda, especificamente na obra analisada, constitui-se a partir das relações de saber e poder que lhes são inerentes, demonstrando-se como uma das formas de "governo dos infelizes" da atualidade. Por meio de seus enunciados e a oferta redundante de técnicas de fácil compreensão, Cury expõe uma vontade de verdade de que só não é feliz quem não quer, contribuindo para as convocações biopolíticas do bem-estar indicadas por Prado (2013). Nesse regime atravessado por relações de saber e poder, a felicidade é continuamente proposta, objetivando o condicionamento dos sujeitos leitores e suas subjetividades, produzidas a partir das novas relações e condições que se estabelecem na contemporaneidade.

\section{REFERÊNCIAS}

ASSOCIAÇÃO NACIONAL DE LIVRARIAS. Diagnóstico ANL do setor livreiro. Disponível em: <http://anl.org.br/web/pdf/diagnostico_setor_livreiro_2012.pdf>. Acesso em: 04.07.2014.

AMOSSY, R. Imagens de si no discurso: a construção do ethos. 2. ed. São Paulo: Contexto, 2011.

BENETTI, M. Análise de discurso como método de pesquisa em comunicação. In: MOURA, C. P.; LOPES, M. I. V. (Orgs.). Pesquisa em comunicação: metodologias e práticas acadêmicas. Porto Alegre: EDIPUCRS, 2016.

$B I R M A N, J$. Muitas felicidades?! O imperativo de ser feliz na contemporaneidade. In Freire Filho, J. (Org.). Ser feliz hoje: reflexões sobre o imperativo da felicidade. Rio de Janeiro: Editora FGV, 2010.

CURY, A. 12 semanas para mudar uma vida. São Paulo: Editora Planeta do Brasil, 2007.

FOUCAULT, M. Microfísica do poder. 26.ed. São Paulo: Graal, 2013. 
FOUCAULT, M. A arqueologia do saber. 8.ed. Rio de Janeiro: Forense Universitária, 2013b.

FOUCAULT, M. A ordem do discurso. 21ed. São Paulo: Loyola, 2011.

FOUCAULT, M. Vigiar e Punir. Tradução Raquel Ramalhete. Petrópolis: Vozes, 2003.

FREIRE FILHO, J. Ser feliz hoje: reflexões sobre o imperativo da felicidade. Rio de Janeiro: Editora FGV, 2010.

GILL, R. Análise de discurso. In.: BAUER, Martin W; GASKELL, George. Pesquisa qualitativa com texto, imagem e som. Petrópolis. RJ: Vozes. 2002.

GREGOLIN, M. R. (Org.). Discurso e mídia: a cultura do espetáculo. São Carlos: Claraluz, 2003.

MAINGUENEAU, D. Ethos, cenografia, incorporação. In: AMOSSY, Ruth. (Org.). Imagens de si no discurso: a construção /do ethos. 2. ed. São Paulo: Contexto, 2011.

MENDES, M. L. G. da C.; OLIVEIRA, G. F. Treine suas emoções, supere-se, seja feliz! Uma análise discursiva do imperativo da superação e da felicidade na literatura de autoajuda. Revista Comunicação, Mídia e Consumo. Ano 10, Vol.10, n.29 p. 161-182 SET./DEZ. 2013.

ORLANDI, E. P. Análise de discurso: princípios e procedimentos. Campinas, SP: Pontes, 1999.

PRADO, L. A. Convocações biopolíticas dos dispositivos comunicacionais. São Paulo: EDUC: FAPESP, 2013.

ROHDEN, F. Prescrições de gênero via autoajuda científica: manual para usar a natureza? In: Ciências na vida - Antropologia da Ciência em Perspectiva. Terceiro nome. São Paulo, 2012.

RÜDIGER, F. Literatura de auto-ajuda e individualismo. Porto Alegre: Editora da Ufrgs, 1996. 
SCHOCH, R. W. A história da (in)felicidade: três mil anos de busca para uma vida melhor. Tradução Elena Gaidano. Rio de Janeiro: BestSeller, 2011.

SODRÉ, M. Best-seller: a literatura de mercado. São Paulo: Ática, 1988.

TUCHERMAN, I. Desvendando um enigma: autoajuda, mídia e biopoder. In: ROCHA, Rose de Melo; CASAQUI, Vander. (Orgs.). Estéticas midiáticas e narrativas do consumo. Porto Alegre: Sulina, 2012. 
AÇÃO MIDIÁTICA, n.16. Jul./Dez. 2018. Curitiba. PPGCOM-UFPR. ISSN 2238-0701

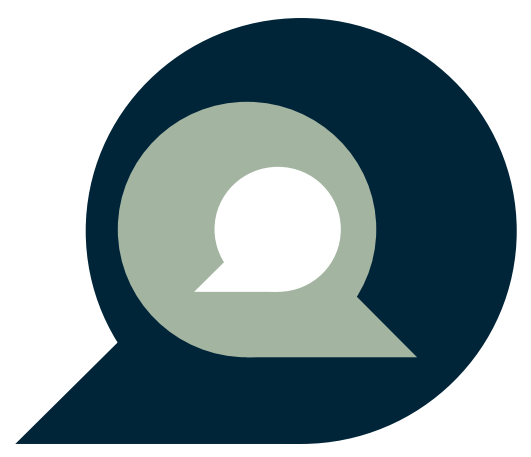

